\title{
Verkeersdeelname in het kader van de WAM: waar liggen de grenzen?
}

\author{
Mr. H.P. Verda $m^{*}$
}

\begin{abstract}
1 Inleiding
Afgelopen zomer wees de Hoge Raad een nieuw arrest met betrekking tot de Wet aansprakelijkheidsverzekering motorrijtuigen (WAM). De zaak betrof een ongeval met een vorkheftruck die werd gebruikt bij het plaatsen van betonnen elementen. ${ }^{1}$ Deze betonnen elementen van zes meter lang werden op een werkplaats een voor een uit de voorraad gehaald en vervoerd naar de plaats waar de elementen op elkaar werden gestapeld. Omdat het zicht van de bestuurder door de gebruikte constructie (waarbij een betonnen element boven op een kist op de vorkheftruck geplaatst was) beperkt was, kwam de vorkheftruck bij het naar voren rijden in aanraking met een betonnen element dat los op de werkvloer stond. Dat element viel om en kwam op de benen van het slachtoffer terecht, met ernstig letsel als gevolg.
\end{abstract}

Vervolgens rees de vraag of hier sprake was van schade die onder de dekking van de WAM-verzekering van de vorkheftruck viel, of niet. In het eerste geval - dus als het ongeval onder de reikwijdte van de WAM valt - kan de benadeelde de betrokken WAM-verzekeraar rechtstreeks aanspreken (de zogenaamde 'directe actie' van art. 6 WAM). De WAM-verzekeraar is richting de benadeelde verplicht om de in de WAM opgenomen dekking te bieden. Voor de reikwijdte van de richting de benadeelde te verlenen dekking zijn de polisvoorwaarden daarom niet zo interessant. In plaats daarvan moet worden gekeken naar de artikelen in de WAM en de achterliggende Europese regelgeving.

Dit artikel beoogt een overzicht te bieden van de huidige stand van zaken op dat vlak. Aanleiding daartoe vormt het hierboven al kort genoemde arrest van de Hoge Raad, en twee recente arresten van het Hof van Justitie van de EU die op een vergelijkbare situatie zien. Om deze arresten van een kader te voorzien zal in dit artikel eerst de bredere context waarbinnen de WAM zich afspeelt, worden geschetst. Vervolgens zal ik ingaan op de reikwijdte van de verplichte WAM-dekking en de in het verleden in dat kader verschenen jurisprudentie, om zo een basis te bieden voor de daaropvolgende bespreking en evaluatie van de recent verschenen arresten van het Hof van
Justitie van de EU en de Hoge Raad. Tot slot wordt afgesloten met een korte conclusie, waarin de belangrijkste elementen van het dekkingsbereik worden samengevat.

\section{De WAM in context: relevante andere regelgeving}

Voordat ik verder inga op de reikwijdte van de verplichte WAM-dekking, is het belangrijk om goed voor ogen te hebben dat de WAM niet op zichzelf staat.

\subsection{Achterliggende Europese regelgeving}

Al sinds haar totstandkoming in 1963 is de WAM nauw verweven met ontwikkelingen over de grenzen. De aanleiding voor het invoeren van de WAM was overleg op Beneluxniveau over een verplichte verzekering voor motorrijtuigen. In 1966 resulteerde dit overleg in een (tweede) Beneluxovereenkomst betreffende de verplichte aansprakelijkheidsverzekering inzake motorrijtuigen, waarmee de Benelux-lidstaten zich verplichtten om in hun wetgeving voorschriften in te voeren die voldoen aan de bij de overeenkomst behorende 'Gemeenschappelijke bepalingen'. ${ }^{2}$ De WAM anticipeerde al op deze regelgeving en is naar aanleiding van de in 1966 tot stand gekomen Benelux-overeenkomst aan de daarbij behorende Gemeenschappelijke bepalingen aangepast.

Daarnaast geldt sinds 1972 ook op Europees niveau een soortgelijke regeling (inmiddels, na enkele eerdere versies, de zogenaamde 'Vijfde' Richtlijn, 2009/103/EG), die lidstaten verplicht om maatregelen te nemen om te zorgen dat de wettelijke aansprakelijkheid met betrekking tot de deelneming aan het verkeer van voertuigen is gedekt. Ook deze Europese regelgeving vindt haar neerslag in de WAM, die, waar nodig, aan de geldende Vijfde Richtlijn is aangepast. Bij de uitleg van de reikwijdte van de onder de WAM geboden dekking moet dus rekening worden gehouden met (de achtergrond van) de bepalingen van de Europese richtlijn en de Gemeenschappelijke bepalingen bij de Benelux-overeenkomst en de uitleg die

\footnotetext{
Mr. H.P. Verdam is advocaat bij Kennedy Van der Laan te Amsterdam. Met dank aan mr. P. van den Broek (tevens advocaat bij Kennedy Van der Laan) voor zijn bereidheid mee te denken en zijn opmerkingen bij de conceptversie van dit artikel.

1. HR 8 juni 2018, ECLI:NL:HR:2018:877, NJ 2018/269.
}

2. De eerste Benelux-overeenkomst was al in 1955 in Brussel gesloten, maar is door Nederland niet geratificeerd. De tweede Benelux-overeenkomst werd in 1966 door Nederland geratificeerd en is in 1967 in werking getreden. 
daaraan door het Gerechtshof van de Benelux (BenGH) en het Europese Hof van Justitie ( $\mathrm{HvJ}$ EU) wordt gegeven. ${ }^{3}$

\subsection{Interactie met het nationale aansprakelijkheidsrecht}

Verder is voor het bereik van de WAM ook de nationale wetgevingscontext van belang. Een van de vereisten voor dekking is namelijk dat er sprake is van 'burgerrechtelijke aansprakelijkheid'. De enkele betrokkenheid van een motorrijtuig is dus onvoldoende voor een aanspraak op een WAM-verzekering: er moet beoordeeld worden of de aansprakelijkheid van de bestuurder, gebruiker of inzittende van de auto in het geding is. ${ }^{4}$ De WAM vestigt daarvoor geen eigen aansprakelijkheidsregime, maar sluit op dat vlak aan bij het op het ongeval toepasselijke (nationale) aansprakelijkheidsrecht. In Nederland is dat voornamelijk te vinden in Boek 6 van het Burgerlijk Wetboek (BW). Daarnaast zal doorgaans veel waarde toekomen aan de geldende verkeersregels, zoals opgenomen in de Wegenverkeerswet 1994 (WVW 1994) en het Reglement Verkeersregels en Verkeerstekens (RVV), waarbij in het bijzonder wordt gewezen op de verregaande aansprakelijkheidsregeling van art. 185 WVW 1994 voor ongevallen tussen gemotoriseerde en ongemotoriseerde verkeersdeelnemers. Een belangrijke kanttekening daarbij is echter dat de WVW 1994 en het RVV alleen van toepassing zijn op de openbare weg (zie art. 2 lid 1 jo. art. 1 lid 1 sub b WVW 1994). Voor ongevallen die niet op de (openbare) weg plaatsvinden, geldt art. 185 WVW 1994 dus niet en zal - ook voor ongevallen met een ongemotoriseerde verkeersdeelnemer - moeten worden gekeken naar de algemene normen van art. 6:162 BW. Bovendien zijn buiten de openbare weg ook de in de WVW 1994 en het RVV opgenomen verkeersregels niet van toepassing. In plaats daarvan zal men moeten toetsen aan de algemene verkeersopvattingen, waarbij de verkeersregels indirect wel een aanknopingspunt kunnen vormen, en de vraag of de handelingen van een of beide verkeersdeelnemers een onaanvaardbare mate van gevaarzetting met zich meebrachten. Het toepassingsbereik van de WVW 1994 en het RVV verschilt in die zin van de WAM, die - zoals hierna nog besproken zal worden - ook geldt bij ongelukken die niet op de openbare weg plaatsvinden. Het is dus van belang dit goed uit elkaar te houden.

\section{De WAM ten opzichte van andere verzekeringen}

Tot zover het wetgevingskader waarbinnen de WAM zich afspeelt. Daarnaast is ook van belang te realiseren dat de WAM niet de enige verzekering is waaronder de schade als gevolg van een verkeersongeval gedekt kan zijn. Te denken valt bijvoorbeeld aan een verkeersongeval dat plaatsvindt tijdens werkverkeer, dat gedekt kan zijn onder de aansprakelijkheidsverzekering (AVB) van de werkgever of een speciale WEGAS (werkgeversaansprakelijkheid)- of WEGAM (werkgeversaan-

3. Het HvJ EU benadrukt dit nogmaals in r.o. 42 van zijn uitspraak van 4 september 2014, ECLI:EU:C:2014:2146 (Vnuk), waarin het zijn eerdere overweging uit eerdere jurisprudentie herhaalt, dat gedragsbepalingen in de gehele EU autonoom en uniform moeten worden uitgelegd.

4. Zie ook De Bosch Kemper, in: GS Onrechtmatige daad, Boek 6 BW, aant. 356.1 sprakelijkheid motorrijtuigen)-verzekering, of een ongeval bij het gebruik van multifunctionele werktuigen, waarvoor naast een WAM-verzekering ook een werkmaterieelverzekering is afgesloten. In dergelijke verzekeringen is vaak een uitsluiting opgenomen voor schade die al onder de WAM-verzekering gedekt is. ${ }^{5}$ Het bepalen van de reikwijdte van de geboden WAM-dekking is dus niet alleen van belang om te bepalen of een benadeelde wel of niet de WAM-verzekeraar direct kan aanspreken, maar ook om de dekking af te bakenen in het geval van (mogelijke) samenloop met andere verzekeringen.

\subsection{De rol van polisvoorwaarden}

Daarbij moet men in het achterhoofd houden dat er een verschil is tussen de WAM als wet en het daaruit voortvloeiende product van de WAM-verzekering zoals dat op de verzekeringsmarkt wordt aangeboden. De wet regelt (enkel) de verplichte minimum-dekking. De door een aansprakelijkheidsverzekering voor motorrijtuigen geboden dekking, zoals die in de polisvoorwaarden is omschreven, kan en mag echter ruimer zijn dan enkel deze verplichte WAM-dekking. In de praktijk bieden WAM-verzekeraars soms een ruimere dekking voor 'door of met' het verzekerde motorrijtuig veroorzaakte schade, zonder de beperking dat dit alleen geldt voor (1) schade in verband met deelneming aan het verkeer, of (2) die schade waarvoor de WAM-verzekeraar wettelijk verplicht dekking moet bieden. ${ }^{6}$ Een dergelijke dekking is ruimer dan de verplichte WAM-dekking. Naast de vraag welke dekking verplicht is, is dus ook van belang om in het oog te houden wat er concreet in de polisvoorwaarden is opgenomen, en of dat niet verder strekt dan de wettelijke regeling. ${ }^{7}$ Dit artikel ziet enkel op de wettelijke kaders (en het aldus verplichte minimum aan dekking zoals die jegens de benadeelde geldt) en laat eventuele afwijkende bepalingen in de polisvoorwaarden verder buiten beschouwing.

\section{De verplichte WAM-dekking}

Het wettelijk kader wordt gegeven in art. 3 WAM, dat de verzekeraar verplicht om dekking te bieden voor 'de burgerrech-

5. Dit kan overigens tot problemen leiden wanneer de in de WAM-verzekering geboden dekking beperkter is dan de in de AVB opgenomen uitsluiting en er aldus een gat ontstaat. In dergelijke gevallen kan een lacune in de (spiegelbeeld)dekking tussen de AVB- en de WAM-verzekering ontstaan, die onder bepaalde omstandigheden voor rekening van de AVBverzekeraar kan komen. Deze materie komt onder andere aan de orde in de arresten NN/Dritty (HR 10 oktober 2003, ECLI:NL:HR: 2003:AF9439) en Excellent/Axa (HR 13 juli 2007, ECLI:NL:HR: 2007:BA7217). In het kader van dit artikel wordt hier echter verder niet op ingegaan.

6. Zie ook De Bosch Kemper, in: GS Onrechtmatige daad, Boek 6 BW, aant. 356.1 en HR 10 oktober 2003, ECLI:NL:HR:2003:AF9439, r.o. 3.5, waarin wordt overwogen dat er in de praktijk WAM-verzekeraars zijn die een ruimere dekking geven dan die waartoe de WAM verplicht.

7. In het algemeen zal daarbij gelden dat het bepalen van de betekenis van een afwijkende polisbepaling voor de reikwijdte van de dekking een kwestie van contractsuitleg zal zijn, waarbij bij eenzijdig opgestelde polisvoorwaarden doorgaans veel waarde gehecht zal worden aan de taalkundige betekenis van de begrippen, mede gezien in het licht van de polis als geheel en de wettelijke context. Zie in dat kader ook HR 16 mei 2008, NJ 2008/284 (Chubb/Dagenstaed) en M.L. Hendrikse, Uitleg van verzekeringsvoorwaarden, NTHR 2008, afl. 4, p. 144-153. 
telijke aansprakelijkheid, waartoe het motorrijtuig in het verkeer aanleiding kan geven'. Over het begrip burgerrechtelijke aansprakelijkheid overwoog ik hierboven al het een en ander. Een succesvol beroep op dekking vereist dat deze aansprakelijkheid (1) gerelateerd is aan het gebruik van een motorrijtuig en (2) verband houdt met deelname aan het verkeer.

\subsection{Schade veroorzaakt door of met een motorrijtuig}

Het begrip 'motorrijtuig' is een cruciaal element, waaraan niet alleen de reikwijdte van de dekking, maar ook de verplichting tot het afsluiten van een WAM-verzekering is gekoppeld. ${ }^{8}$ Volgens de officiële definitie is een motorrijtuig elk voertuig 'bestemd om anders dan langs spoorstaven te worden voortbewogen uitsluitend of mede door een mechanische kracht, op of aan het voertuig zelf aanwezig dan wel door elektrische tractie met stroomtoevoer van elders' (art. 1 WAM en art. 1 sub c WVW 1994). Naast een auto omvat dit begrip dus ook voertuigen zoals een motorfiets, snorfiets of scootmobiel. Voertuigen die langs het spoor bewegen, zoals treinen, trams of de metro, kwalificeren daarentegen niet als motorrijtuig.

Aan deze definitie wordt in de WAM verder nog toegevoegd dat een los element dat aan het rij- of voertuig gekoppeld is, of daarvan na koppeling is losgemaakt of losgeraakt, nog als onderdeel van het motorrijtuig geldt zolang dit onderdeel niet (veilig) buiten het verkeer tot stilstand is gekomen (art. 1 WAM). Daarbij moet bijvoorbeeld worden gedacht aan een losgekoppelde aanhangwagen, die door een motorrijtuig op de vluchtstrook geparkeerd is en daar een risico voor andere verkeersgebruikers vormt. ${ }^{9}$ Hetzelfde geldt voor lading die van het motorrijtuig valt: als deze lading tijdens het rijden van de wagen valt en vervolgens schade veroorzaakt, moet dit gezien worden als schade veroorzaakt door het motorrijtuig. ${ }^{10}$

\subsection{Het begrip verkeersdeelname}

Dat er naast schade veroorzaakt door of met een motorrijtuig ook sprake moet zijn van een verband met deelname aan het verkeer, dient vooral ter afbakening ten opzichte van ongevallen met motorrijtuigen die enkel als werktuig gebruikt worden, en niet aan het verkeer deelnemen. De Nederlandse wetgever overwoog hierover in 1983:

'Voorts is van de gelegenheid gebruik gemaakt een vraag op te lossen, die (...) in de praktijk is gerezen, namelijk of de verzekering alleen dekking moet geven voor aansprakelijkheid voor verkeersongevallen, of dat zij ook aansprake-

8. Art. 2 lid 1 WAM verplicht de bezitter van een motorrijtuig dat aan het verkeer deelneemt en/of in het kentekenregister staat ingeschreven een WAM-verzekering af te sluiten. Dit geldt óók voor een voertuig dat niet langer gebruikt wordt, zo blijkt uit het recente arrest van het HvJ EU van 4 september 2018 (ECLI:EU:C:2018:661), waarin het Hof oordeelde dat ook een voertuig verzekeringsplichtig blijft zolang het niet onklaar is gemaakt of is uitgeschreven.

9. HR 16 maart 1979, ECLI:NL:HR:1979:AC6516, NJ 1980/76 (Staat/ Ennia).

10. Zie ook HR 2 januari 1970, ECLI:NL:HR:1970:AB3459, NJ 1970/162 (Afgevallen kist) lijkheid moet dekken die ontstaat door het aanrichten van schade buiten het verkeer, bij voorbeeld door het gebruik van bepaalde soorten motorrijtuigen als graaf- of hijswerktuig. (...) De voorgestelde tekst maakt nu duidelijk dat de verplichting tot verzekering slechts bestaat met betrekking tot de aansprakelijkheid voor verkeersongevallen, door invoeging van de woorden "in het verkeer".

(...) De term "in het verkeer" moet niet zó beperkt worden opgevat, dat daaronder alleen wordt begrepen schade, die door het verzekerd motorrijtuig wordt toegebracht, wanneer het zelf in beweging is: daaronder valt bijvoorbeeld ook de schade die ontstaat doordat het - stilstaande - verzekerde motorrijtuig verkeerd staat geparkeerd. Evenzeer valt daaronder verkeersschade die bij voorbeeld wordt toegebracht door over de weg rijdende graaf- en hijswerktuigen, echter niet de schade die door deze werktuigen bij de uitvoering van werkzaamheden wordt veroorzaakt, zoals kabelschade.'11

Van een ongeval 'waartoe het motorrijtuig in het verkeer aanleiding kan geven', is doorgaans snel sprake. Zoals uit het citaat hierboven al blijkt, is niet vereist dat het motorrijtuig ook aan het rijden was: ook een stilstaand motorrijtuig of een motorrijtuig dat aan de hand wordt meegenomen, kan schade zoals bedoeld in de WAM veroorzaken. ${ }^{12}$ Een klassiek voorbeeld is het Hoge Raad-arrest van 9 januari 1976, dat betrekking had op een bromfietser die van zijn bromfiets afgestapt was omdat er een spijker in zijn band zat en zich over zijn bromfiets had gebogen, waardoor een andere bromfietser met hem in botsing kwam en hoofdletsel opliep. ${ }^{13}$ De Hoge Raad oordeelde dat dit ongeval in zodanig nauw verband stond met de risico's verbonden aan het per bromfiets deelnemen aan het verkeer, dat de aldus opgelopen schade onder de WAM gedekt was. Meer recent, maar minstens zo beeldend, is een zaak waarin een bestuurder op de snelweg een haas aanrijdt, om vervolgens uit te stappen en de weg op te lopen om de haas op te rapen, waarna hij aangereden wordt. ${ }^{14}$ Ook daar was sprake van verkeersdeelname. Voor een succesvol beroep op dekking lijkt voldoende dat het gaat om de verwezenlijking van risico's die voortvloeien uit het deelnemen aan het verkeer, ook als het motorrijtuig op het moment van het ongeval al tot stilstand is gekomen. ${ }^{15}$

\section{Multifunctionele voertuigen}

De meeste discussie over het begrip 'verkeersrisico' bestaat in de praktijk rondom het gebruik van multifunctionele voertui-

11. Kamerstukken II 1976/77, 14281, 1-4, p. 16 en 17.

12. Zie onder meer HR 12 januari 1979, ECLI:NL:HR:1979:AC2297, NJ 1979/291 en BenGH 15 december 2003, ECLI:NL:XX:2003:AP0083, NJ 2004/279.

13. HR 9 januari 1976, ECLI:NL:HR:1976:AB4216 (CWB/Wet-Risico), NJ 1976/310 m.nt. A.R. Bloembergen.

14. HR 10 februari 2006, ECLI:NL:HR:2006:AU5702.

15. Vgl. ook Keirse in haar noot bij laatstgenoemd arrest (HR 10 februari 2006, ECLI:NL:HR:2006:AU5702, NTBR 2006/202 m.nt. A.L.M. Keirse). 
gen die aan het verkeer kunnen deelnemen, maar ook als werktuig gebruikt kunnen worden. Wanneer vallen deze ongevallen wel en niet onder de WAM-dekking? De recent verschenen arresten van de Hoge Raad en het Hof van Justitie hebben betrekking op deze afbakening tussen de verkeersfunctie en de werktuigfunctie van een multifunctioneel voertuig. Voordat ik verder inga op deze recente ontwikkelingen, zal ik - om deze ontwikkelingen in het juiste historisch perspectief te plaatsen - echter eerst twee oudere arresten bespreken die op deze materie betrekking hebben. Deze arresten vormen de basis waarop de huidige arresten (deels) voortbouwen.

\subsection{Het Benelux-Hof: schade veroorzaakt op een wijze karakteristiek voor het verkeer}

Het klassieke arrest op Benelux-niveau is het zogenaamde Vorkheftruck-arrest uit $1984 .{ }^{16}$ Aanleiding voor dit arrest waren de prejudiciële vragen van de Nederlandse Hoge Raad over een ongeval met een vorkheftruck die in een loods pallets met balen rijst aan het opstapelen was. ${ }^{17}$ Een van de balen rijst viel bij het verplaatsen van de vorkheftruck op een persoon die naast de vorkheftruck stond, die daardoor gewond raakte. Het Gerechtshof van de Benelux overwoog in zijn oordeel dat de WAM-verzekering alleen dekking hoeft te verlenen als de schade veroorzaakt is 'op een wijze die karakteristiek is voor het verkeer'. ${ }^{18}$ Daaraan voegde het Hof toe dat het feit dat een motorrijtuig tegelijkertijd als werktuig wordt gebruikt, er niet aan in de weg hoeft te staan dat de schade toch kan worden aangemerkt als in het verkeer veroorzaakt. In deze zaak kwam het Hof uiteindelijk echter toch tot het oordeel dat de wijze waarop de schade veroorzaakt was niet karakteristiek was voor schadeveroorzaking in het verkeer, omdat het verplaatsen van de vorkheftruck in dit geval slechts gezien kon worden als onderdeel van de manoeuvre waarbij het motorrijtuig als werktuig werd gebruikt.

\subsection{Het Hof van Justitie van de EU: gebruik overeenkomstig de gebruikelijke functie}

Op Europees niveau kwamen vragen over de dekking voor ongevallen veroorzaakt door multifunctionele voertuigen aan de orde in het arrest Vnuk, dat op 4 september 2014 door het Hof van Justitie van de EU gewezen werd. ${ }^{19}$ Het arrest had betrekking op een tractor met aanhangwagen die gebruikt werd voor het opstapelen en verplaatsen van hooibalen in een hooischuur van een boerderij. Om de schuur binnen te rijden reed de tractor op de binnenplaats van de boerderij een stuk achteruit. Daarbij reed de tractor tegen een ladder, waar een man op stond (Vnuk) die van de ladder viel en letsel opliep. Vnuk richtte zich voor de vergoeding van zijn schade rechtstreeks tot de WAM-verzekeraar van de tractor. Deze stelde echter dat de geleden schade niet onder de WAM-verzekering

\footnotetext{
16. BenGH 23 oktober 1984, ECLI:NL:XX:1984:AD6462, NJ 1986/458 (Vorkheftruck).

17. HR 8 april 1983, ECLI:NL:HR:1983:AJ4948, NJ 1986/457 (Vorkheftruck I).

18. BenGH 23 oktober 1984, ECLI:NL:XX:1984:AD6462, NJ 1986/458 (Vorkheftruck).

19. HvJ EU 4 september 2014, ECLI:EU:C:2014:2146 (Vnuk).
}

gedekt was, omdat er geen sprake was van deelname aan het verkeer.

Cruciaal punt in de discussie was de vraag of het begrip 'deelneming aan het verkeer' beperkt was tot de openbare weg, of dat ook het gebruik van een tractor op privéterrein daaronder zou kunnen vallen. Het Hof van Justitie gaf daarop aan dat de reikwijdte van de WAM niet beperkt is tot de openbare weg, maar ook geldt voor gebruik dat elders, bijvoorbeeld op privéterrein, plaatsvindt. ${ }^{20}$ Gezien de doelstelling om verkeersslachtoffers te beschermen, moet elk gebruik van een voertuig dat 'overeenstemt met de gebruikelijke functie van dat voertuig' onder de WAM gedekt zijn, aldus het Hof. In dit geval betrof dat het achteruitrijden van een voertuig om zich op een bepaalde plaats te positioneren. Een dergelijke manoeuvre kan volgens het Hof, ook als dit niet op de openbare weg gebeurt, overeenstemmen met de gebruikelijke functie van een voertuig en valt aldus onder de verplichte WAM-dekking.

Kortom: rijden of bewegen om zich op een bepaalde plaats te positioneren geldt als deelname aan het verkeer, ongeacht de plaats waarop dit gebeurt. ${ }^{21}$ Het hierboven besproken oordeel van het Gerechtshof van de Benelux in zijn arrest uit 1984 lijkt daarmee achterhaald: immers, ook in die zaak was sprake van het bewegen om zich op een bepaalde plaats te positioneren en zou volgens de door het Hof van Justitie van de EU gegeven maatstaf dus sprake zijn van deelname aan het verkeer.

\section{Nieuwe jurisprudentie: verdere verduidelijking van het verkeerscriterium}

Het criterium dat er sprake is van verkeersdeelname als het gebruik van een voertuig overeenstemt met de 'gebruikelijke functie' van dat voertuig, bleek in de praktijk echter tot onduidelijkheid te leiden. In de literatuur vroeg men zich bijvoorbeeld af of er bij gebruik van een multifunctioneel voertuig, dat zowel als voertuig alsook als werktuig kan dienen, altijd sprake was van gebruik conform de 'gebruikelijke functie', en dus van WAM-dekking, of dat daarvan geen sprake was indien het voertuig niet primair als voertuig werd gebruikt. ${ }^{22}$ Deze

20. Dit is later nogmaals bevestigd in de arresten HvJ EU 28 november 2017, C-514/16, ECLI:EU:C:2017:908 (Rodrigues de Andrade) en HvJ EU 20 december 2017, C-334/15, ECLI:NL:EU:C:2017:1007 (Torreiro).

21. Het BenGH was in het Vorkheftruck-arrest iets terughoudender op dit vlak en overwoog dat voor het antwoord op de vraag of de schade is veroorzaakt op een wijze die karakteristiek is voor schadeveroorzaking door een motorrijtuig in het verkeer, van belang kan zijn of de schade is veroorzaakt op een voor het verkeer bestemde weg, dan wel op een bedrijfsterrein. In het eerste geval (bij schade op een voor het verkeer bestemde weg) zal eerder sprake zijn van schadeveroorzaking die karakteristiek is voor schadeveroorzaking door een motorrijtuig in het verkeer dan in het tweede geval.

22. Zie J.H. Wansink, Hoe helder is de Europese invulling van het WAMbegrip 'deelneming aan het verkeer van motorrijtuigen', AV\&S 2015/8 en de conclusie van A-G Vlas bij HR 8 juni 2018, ECLI:NL:HR: 2018:877, waarin deze in eerste instantie (voordat hij door een van de partijen op het recente arrest van het HvJ EU werd gewezen) constateerde dat er in dit opzicht geen sprake was van een 'acte éclairé' en adviseerde tot het stellen van een prejudiciële vraag (par. 2.18). 
onduidelijkheid leidde in de afgelopen periode tot enkele nieuwe arresten, waarin de afbakening van deelname aan het verkeer enerzijds en de werkfunctie van een werktuig anderzijds opnieuw aan de orde komen.

Zo wees het Hof van Justitie van de EU eind 2017 twee nieuwe WAM-arresten, die in het Hoge Raad-arrest van deze zomer aangehaald worden. Dit betreft allereerst het arrest Rodrigues de Andrade van 28 november 2017. ${ }^{23}$ Aanleiding voor dit arrest was een ongeval met een landbouwtractor. Deze tractor stond stil op een landweggetje langs de wijngaarden, terwijl de motor van de tractor draaide om de pomp voor het sproeien van een bestrijdingsmiddel aan te drijven. Door trillingen van de motor, in combinatie met de zware regenval die dag, ontstond een grondverschuiving, waarbij de tractor werd meegesleurd en uiteindelijk op een werknemer terechtkwam. Aan het Hof van Justitie werd de (prejudiciële) vraag voorgelegd of er in een dergelijk geval sprake was van 'deelneming aan het verkeer'. Het Hof overweegt - onder verwijzing naar het Vnuk-arrest - dat niet bepalend is op welk terrein het ongeval plaatsvond. Het criterium is of er sprake was van gebruik volgens de gebruikelijke functie, dat wil zeggen: gebruik van een voertuig 'als vervoermiddel' - dus als middel om mensen of lading mee te vervoeren. Daarbij merkt het Hof op dat ook bij een stilstaand voertuig van dergelijk vervoer sprake kan zijn. Hiermee bevestigt het Hof van Justitie de in Nederland al langer bekende regel dat bij de invulling van dat verkeersbegrip niet doorslaggevend is of het motorrijtuig rijdt. Gelet op het feit dat de motorkracht van de tractor ten tijde van het ongeval gebruikt werd voor het sproeien van bestrijdingsmiddel, komt het Hof echter tot het oordeel dat hier geen sprake was van gebruik van de tractor in de functie van vervoermiddel, maar van gebruik van de tractor als machine. Het ongeval met de tractor houdt daarom geen verband met het verkeer.

Een maand later volgde een tweede arrest ('Torreiro') waarin de aard van het terrein waarop een ongeval plaatsvond nog eens aan de orde werd gesteld. ${ }^{24}$ In dat arrest, waarin sprake was van een ongeval met een militair terreinvoertuig op wielen, oordeelt het Hof dat de omstandigheid dat een ongeval plaatsvond op een militair terrein, dat niet toegankelijk was voor niet-militaire voertuigen en niet geschikt was voor voertuigen op wielen, niets afdoet aan de conclusie dat er sprake was van gebruik van het voertuig als vervoermiddel. Schade ontstaan door het rijden op wegen of terreinen die niet voor verkeer geschikt zijn, mag niet van dekking worden uitgesloten.

De Europese Commissie heeft op 24 mei 2018 laten weten dat zij voornemens is de in deze arresten gegeven regels over het

23. HvJ EU 28 november 2017, C-514/16, ECLI:EU:C:2017:908.

24. HvJ EU 20 december 2017, C-334/15, ECLI:NL:EU:C:2017:1007 (Torreiro). toepassingsgebied van de WAM te codificeren in de Richtlijn motorrijtuigenverzekering. ${ }^{25}$

\section{Het Hoge Raad-arrest van 8 juni 2018}

Ook in Nederland heeft de onduidelijkheid over het criterium van 'gebruik conform de gebruikelijke functie' tot een nieuw arrest geleid. ${ }^{26}$ Dat arrest van 8 juni 2018 bouwt voort op de hierboven besproken arresten van het Hof van Justitie van de EU. A-G Vlas stelde in zijn conclusie bij dit arrest van 8 juni 2018 in eerste instantie zelfs voor om over dit onderwerp een prejudiciële vraag aan het Hof van Justitie van de EU te stellen, maar paste zijn conclusie aan nadat een van de procespartijen hem op het recent verschenen Andrade-arrest wees. ${ }^{27}$

Zoals in de inleiding van deze bijdrage al kort besproken werd, heeft het Hoge Raad-arrest van deze zomer betrekking op een vorkheftruck die bij het rijdend verplaatsen van betonnen elementen een ander, losstaand element doet omvallen op de benen van het slachtoffer. De kantonrechter oordeelde dat dit ongeval niet onder de WAM-dekking viel, omdat er geen sprake was van een gedraging die typisch is voor deelname aan het verkeer. Het Hof kwam tot een ander oordeel: omdat er sprake was van het vervoeren van betonnen elementen en schade veroorzaakt door het naar voren rijden, was er volgens het Hof sprake van gebruik van het voertuig conform de gebruikelijke functie daarvan en dus van verkeersdeelname in de zin van de WAM. De Hoge Raad bevestigt het oordeel van het Hof en verwijst daarbij naar de arresten Andrade en Vnuk, waaruit volgt dat het van de omstandigheden van het geval afhangt of een motorrijtuig wordt gebruikt om deel te nemen aan het verkeer of als werktuig. Volgens de Hoge Raad is het Hof kennelijk uitgegaan van gebruik als vervoermiddel en heeft het dat voldoende gemotiveerd.

A-G Vlas was tot een ander oordeel gekomen en overwoog daartoe het volgende:

'Uit deze prejudiciële beslissing van het HvJEU volgt dat het hof in het thans in cassatie bestreden arrest ten onrechte als uitgangspunt heeft genomen dat met betrekking tot een multifunctioneel motorrijtuig niet behoeft te worden onderzocht of de schade is veroorzaakt op een wijze die karakteristiek is voor schadeveroorzaking door een motorrijtuig in het verkeer. Zoals volgt uit het arrest Rodrigues de Andrade is het immers met betrekking tot een multifunctioneel motorrijtuig, zoals een vorkheftruck in de onderhavige zaak, van belang te onderzoeken of een dergelijk voertuig op het moment waarop het bij een ongeval betrokken raakte voornamelijk als vervoermiddel werd gebruikt of als machine. Alleen in het eerste geval valt het gebruik van het voertuig onder het begrip "deelneming aan

25. Wetsvoorstel d.d. 24 mei 2018, COM(2018)336 - 2018/0168 (COD),

26. HR 8 juni 2018, ECLI:NL:HR:2018:877, NJ 2018/269.

27. Conclusie A-G Vlas bij HR 8 juni 2018, ECLI:NL:PHR:2018:86 en ECLI:NL:PHR:2018:184. Zie met name par. 1.1 van de laatstgenoemde conclusie. 


\section{Maandblad}

het verkeer" in de zin van art. 3 lid 1 WAM en valt daarmee het ongeval waarbij het voertuig betrokken was onder de dekking van de verplichte WAM aansprakelijkheidsverzekering.

Gelet op het voorafgaande geeft het oordeel van het hof in rov. 3.4.3 dat het begrip "deelneming aan het verkeer van voertuigen" mede omvat "elk gebruik van een voertuig dat overeenstemt met de gebruikelijke functie ervan" en dat hierbij niet relevant is of de vorkheftruck aan het rijden was ten tijde van het ongeval, blijk van een onjuiste rechtsopvatting. (...). ${ }^{, 28}$

Kortom: volgens A-G Vlas heeft het Hof helemaal niet onderzocht of het voertuig wel of niet als vervoermiddel werd gebruikt. Dat de Hoge Raad in het oordeel van het Hof wél leest dat het Hof daarnaar onderzoek verricht zou hebben, is wellicht ingegeven door de omstandigheid dat het oordeel waarop het Hof uiteindelijk uitkomt juist lijkt - ook als de toegepaste toets niet helemaal juist of helder is. $\mathrm{Nu}$ de vorkheftruck aan het rijden was om de betonnen elementen van de ene kant van de ruimte naar de andere kant te brengen, is immers duidelijk dat een onderzoek naar de vraag of er sprake was van gebruik als vervoermiddel tot de conclusie zou leiden dat er inderdaad sprake van vervoer was en dus van dekking onder de WAM. Zoals hiervoor is aangegeven, volgt uit het Vnuk-arrest immers dat rijden of bewegen om zich op een bepaalde plaats te positioneren in principe is te kwalificeren als deelname aan het verkeer.

Ik ben het echter met A-G Vlas eens dat de toevoeging van het Hof, dat niet relevant zou zijn of de vorkheftruck ten tijde van het ongeval aan het rijden was, ${ }^{29}$ onjuist lijkt. Dat zou betekenen dat als de vorkheftruck ten tijde van het ongeval stilstond en de lading niet tijdens het rijden, maar tijdens het omhoogheffen van de lepels waarop de lading zich bevond met een betonnen element in aanraking was gekomen, ook zonder meer sprake zou zijn geweest van gebruik als vervoermiddel. Deze hypothetische situatie valt te vergelijken met het eerder door Wansink aangehaalde voorbeeld van een (verankerde) mobiele kraanwagen, die door een ongelukkige manoeuvre bij het verplaatsen van bouwmateriaal door de lucht schade toebrengt. ${ }^{30}$ Het zou vreemd zijn als dit gebruik als 'verkeersdeelname' wordt gekwalificeerd, terwijl precies dezelfde manoeuvre bij een niet-mobiele kraan niet als verkeersdeelname zou worden gezien. Ik ben het dan ook met Wansink eens dat een dergelijk arbitrair onderscheid tussen werktuigen met en zonder voertuigfunctie niet goed valt te billijken.
Anderzijds kan ten opzichte van het Hof worden toegegeven dat zijn overweging in die zin juist is, dat uit eerdere jurisprudentie en het Andrade-arrest inderdaad volgt dat op zichzelf niet doorslaggevend is of een motorrijtuig rijdt of stilstaat. Ik zou echter willen betogen dat deze regel niet zó ver strekt, dat een dergelijke omstandigheid nooit van enige betekenis zou kunnen zijn, terwijl de redenering van het Hof dat wel lijkt te indiceren.

Zoals ik hierboven al overwoog, geldt dat het uiteindelijke oordeel van het Hof in deze casus wel begrijpelijk lijkt, nu de vorkheftruck in kwestie wél reed. Dat de Hoge Raad - die een dergelijke waardering van omstandigheden slechts op begrijpelijkheid mag toetsen - dit oordeel sanctioneert, mag wellicht dan ook niet verbazen. Gezien de summiere toelichting van het Hof, waarin niet expliciet getoetst wordt of er sprake is van gebruik als vervoermiddel, schept dit oordeel echter weinig duidelijkheid voor de praktijk. De lijn tussen wel of geen verkeersdeelname lijkt dun en heeft nog altijd geen scherp gedefinieerde grenzen. Duidelijk is in elk geval wel dat ook bij werktuigen geldt dat het begrip verkeersdeelname ruim is: van WAM-dekking is dus - ook bij de uitvoering van werkzaamheden buiten de weg - snel sprake.

\section{Conclusie}

De nieuwe arresten over de reikwijdte van de verplichte WAM-dekking brengen dus weinig verandering in de al geldende regels: het bereik van de WAM is en blijft ruim. Wel worden de bestaande regels bevestigd en, tot op zekere hoogte, verduidelijkt. Van belang is daarbij dat de WAM, anders dan bijvoorbeeld de WVW 1994, ook op andere terreinen dan de openbare weg geldt: niet de plaats van het ongeval, maar de vraag of het motorrijtuig als vervoermiddel wordt gebruikt, is bepalend. Wordt er met materialen gereden of beweegt het motorrijtuig om zich op een bepaalde plek te positioneren, dan zijn de daaruit voortvloeiende ongevallen en schades gedekt onder de WAM-verzekering. Hetzelfde geldt als de schade ontstaat door een risico dat samenhangt met gemotoriseerde verkeersdeelname, zoals een ongeval als gevolg van het uitstappen na een aanrijding of het haperen van de motor. Pas als er evident geen sprake van 'vervoer' of een daarmee samenhangend risico is - zoals in het geval van een stilstaande tractor waarvan de motor als krachtbron voor een sproei-installatie wordt gebruikt -, kan een schade van dekking worden uitgesloten. Waar in dat kader precies de grens ligt, is echter nog altijd voor discussie vatbaar.

28. Conclusie A-G Vlas bij HR 8 juni 2018, ECLI:NL:PHR:2018:184, par. 2.6 en 2.7 .

29. Hof's-Hertogenbosch 6 december 2016, ECLI:NL:GHSHE:2016:5402, r.o. 3.4.3: 'Voor alle duidelijkheid merkt het hof op dat dit oordeel geldt zowel in het geval de vorkheftruck aan het rijden was ten tijde van het ongeval als in het geval de vorkheftruck niet aan het rijden was.'

30. Wansink 2015. 